\title{
The Effects of Different Levels of Sunflower Hulls on Reproductive Performance of Yearly Ewes Fed with Pelleted Complete Diets
}

\author{
Abdualrahman S. Alharthi ${ }^{1}{ }^{D}$, Mohsen M. Alobre $^{1}{ }^{\mathbb{D}}$, Mutassim M. Abdelrahman $^{1}$, Hani H. Al-Baadani ${ }^{1}$, \\ Ayman A. Swelum ${ }^{1} \mathbb{D}$, Rifat Ullah Khan ${ }^{2}$ and Ibrahim A. Alhidary ${ }^{1, *(\mathbb{D}}$ \\ 1 Department of Animal Production, Faculty of Food and Agriculture Sciences, King Saud University, \\ P.O. Box 2460, Riyadh 11451, Saudi Arabia; abalharthi@ksu.edu.sa (A.S.A.); malobre@ksu.edu.sa (M.M.A.); \\ amutassim@ksu.edu.sa (M.M.A.); hsaeed@ksu.ed.sa (H.H.A.-B.); aymanswelum@zu.edu.eg (A.A.S.) \\ 2 College of Veterinary Sciences, Faculty of Animal Husbandry and Veterinary Sciences, \\ The University of Agriculture, Peshawar 25000, Pakistan; rukhan@aup.edu.pk \\ * Correspondence: ialhidary@ksu.edu.sa
}

Citation: Alharthi, A.S.; Alobre, M.M.; Abdelrahman, M.M.;

Al-Baadani, H.H.; Swelum, A.A.;

Khan, R.U.; Alhidary, I.A. The Effects of Different Levels of Sunflower Hulls on Reproductive Performance of Yearly Ewes Fed with Pelleted Complete Diets. Agriculture 2021, 11, 959. https://doi.org/10.3390/ agriculture11100959

Received: 23 July 2021

Accepted: 29 September 2021

Published: 2 October 2021

Publisher's Note: MDPI stays neutral with regard to jurisdictional claims in published maps and institutional affiliations.

Copyright: (C) 2021 by the authors. Licensee MDPI, Basel, Switzerland. This article is an open access article distributed under the terms and conditions of the Creative Commons Attribution (CC BY) license (https:/ / creativecommons.org/licenses/by/ $4.0 /)$.

\begin{abstract}
In this study, 84 pregnant ewes were used and randomly distributed to one of four treatments, as follows: C (control), total mixed ration (TMR) $+12 \%$ SFH (S12), TMR $+20 \%$ SFH (S20), and TMR $+28 \%$ SFH (S28). Treatments had a significant $(p<0.05)$ effect on the daily feed intake (DFI) of the ewes during the late gestation ( $30 \mathrm{~d}$ prepartum) and post-partum period, with the S12 and S20 groups having lower feed intake $(35 ; 60 \%)$ than the C and S28 group. The DFI was significantly $(p<0.05)$ low during late gestation in comparable with other periods. The results revealed that body weight (BW) at late gestation was significantly $(p<0.05)$ higher than the BW at 60 -days postpartum and during the mating period. Body condition score (BCS) was significantly $(p<0.05)$ higher during late gestation in comparison with other periods. There was no significant effect of different levels of $\mathrm{SFH}$ on reproductive parameters except S/C, which was significantly higher in the S20 than other groups. Serum glucose level was significantly $(p<0.05)$ higher in the S20 group than the C, S12, and S28 groups during 30 days postpartum. S20 and S28 groups showed a significant $(p<0.05)$ increase in glucose levels at parturition in comparison with other reproductive periods. At late gestation, a significantly $(p<0.01)$ higher concentration of blood NEFA was reported for ewes from the $C$ group compared with other groups. Furthermore, significantly lower $(p<0.05)$ NEFA levels at parturition were found for ewes from the S20 group compared with the S12 group. In conclusion, TMR is not preferable to be used alone in the late gestation period. Sunflower hull can be used as a cheap source of fiber in TMR without adverse effects on health or the reproductive traits of ewes. The increasing level of sunflower hull up to $28 \%$ can affect fertility and increase the number of services per conception, probably due to its high content of lignin (phytoestrogen).
\end{abstract}

Keywords: Awassi ewes; blood biochemistry; conception; pregnancy; post-partum

\section{Introduction}

There has been a decreasing forage supply in recent years due to increasing grassland degradation in many countries throughout the world [1]. Forage crops are essential for sustaining animal production (meat and milk) to meet the needs of the growing population. Alfalfa hay and wheat straw (WS) are widely used as the main ingredients and as fiber sources for ruminants, especially for ewes, in several feed manufacturers throughout the world [2].

Alfalfa hay is an excellent source of digestible proteins, minerals, and vitamins for ruminants. It is a very important ingredient in ruminant nutrition due to its excellent nutritional components, including digestible protein, vitamins, and minerals [3]. Moreover, it is the main source of physically effective neutral detergent fiber (NDF), which showed 
greater rumen buffering capacity than corn silage, Timothy hay, and wheat straw. As per the new Saudi Arabia policy, alfalfa cultivation will be stopped within the next two years to maintain groundwater resources. Therefore, using other dietary fiber resources, including plant byproducts such as sunflower hulls $(\mathrm{SFH})$, can be a suitable solution to solve the shortage of forages due to their higher availability and cheaper price. The total global production of sunflower seeds increased significantly compared with other oilseeds, which reached about 445 million tons; the hulls represent about 13.35 million tons during the year [4].

The nutritional status of ewes has a great impact on their reproductive performance (from mating to lambing). It is well-documented that maternal nutrition plays an important role in fetal growth and development, especially at late gestation [5]. In Saudi Arabia, most of the sheep are raised under traditional or semi-intensive system that depend mainly on barley and alfalfa hay as the main source of nutrients. The traditional production system may negatively affect the reproductive efficiency and, consequently, the high mortality rate of newborns, since the nutrient requirements are not covered during the late gestational and post-partum periods (which could result in severe economic losses) [6]. In general, ewes' productivity is below their genetic potentials due to many suppressing factors, including undernutrition during the critical physiological conditions (such as gestation and lactation). Total mixed ration (TMR) can be used to supply pregnant ewes with their daily nutrient requirements to achieve the targeted reproduction efficiency. Using unconventional feedstuffs for ruminants, such as plant byproducts, may significantly contribute to reducing both feed costs and environmental pollution. However, the main obstacle for using these byproducts as the main source of fiber is the presence of different anti-nutritional factors, such as tannin and lignin. Hence, to efficiently use plant byproducts without negative effects on the ruminants' performance during late gestation and early lactation, their nutritional limitations must be exploited through feeding trials and testing different levels to identify the best choice [7]. The objective of this study was to evaluate the effects of feeding three levels $(12 \%, 20 \%$, and $28 \%$ ) of SFH as a main source of NDF in the TMR diet on the reproductive performance of pregnant Awassi ewes during late gestation and early lactation.

\section{Materials and Methods}

\subsection{Animals Management}

A total of 84 yearly Awassi ewes of similar body weight (BW: $41.12 \pm 4.8 \mathrm{~kg}$ ), age (7-8 months-old) and body condition score (BCS: 2.88) was included in the present study and housed in The Experimental Station of the Animal Production Department, College of Food and Agriculture Sciences, King Saud University, Riyadh. Fourteen days before the study commenced (pre-experimental period), the ewes were weighed, and divided into twelve replicates of seven ewes each and housed in shaded pens ( $6.5 \mathrm{~m}$-long $\times 6.0 \mathrm{~m}$-wide) to be adapted to the pens and the basal diets. Each pen was equipped with a feed trough and a water bucket for group feeding. All ewes were offered the same diet containing $1.95 \mathrm{Mcal}$ of $\mathrm{ME}$ and $13.0 \%$ crude protein $(\mathrm{CP}) / \mathrm{kg}$ (dry matter (DM) basis) at maintenance level $(2.0 \%$ of the initial body weight [8] twice daily at $800 \mathrm{~h}$ and $1500 \mathrm{~h}$. Water was available ad libitum. Twelve mature fertile rams wer allowed with ewes at a rate of $1 \mathrm{ram} /$ replicate.

\subsection{Experimental Design and Diets}

The animals used in the experiment were divided into four groups. At the start of the experimental period, three replicates of ewes ( $n=7 /$ replicate) were randomly allocated to one of four dietary treatments (21 ewes/group): TMR containing 0\% SFH (Control: C), TMR containing S12\% SFH (S12) TMR containing 20\% SFH (S20), and TMR containing $28 \%$ SFH at a level (S28). The experiment was conducted started during breeding season by mating period and continued during pregnancy until delivery and ended 60-days post-partum. 


\subsection{Feed Intake, Body Weight and Body Condition Score}

The weights of offered feed and feed refusals were measured weekly at mating period (60 days started from joining of rams), late gestation period (from day 90 post mating until delivery), parturition day, first 30-days postpartum, and second 30-days postpartum. Then, daily feed intake (DFI) was calculated on a DM basis by dividing the total feed intake in the period on the number of days in the same period.

Ewes were weighed, using an electronic small animal scale for sheep, before the morning feeding at 0730 on the first day of the experiment and every month thereafter until 60-days postpartum. Body condition score (BCS), as an indicator for the nutritional status of pregnant ewes, was recorded for all ewes at the same time as the weighing process during two stages (late gestation and 30-day postpartum). BCS was scored as 1-5:1, emaciated $=2$, thin $=3$, good $=4$, fat, and $5=$ obese [9].

\subsection{Reproductive Performance}

The ewes were housed with rams at a rate of (one ram per replicate which had seven ewes) and left for three subsequently estrous cycles. The mating time was recorded for each ewe. Pregnancy was diagnosed ultrasonographically at day 23 post insemination using multi-frequency linear trans-rectal probe (Model UST-660-7.5, Aloka, Japan) and confirmed at day 35 and 60 using multi-frequency convex abdominal probe (Model UST-9137C, Aloka, Japan). The number of fetus born were recorded and confirmed at lambing. Pregnancy rate (pregnant ewes detected by ultrasound/mated ewes*100), twining rate (ewes lambed twins/pregnant ewes*100), lambing rate (lambed ewes/mated ewes*100), fecundity rate (newborn lambs/mated ewes*100) and prolificacy (newborn lambs/pregnant ewes*100) were calculated.

\subsection{Blood Samples Collection and Analysis}

Blood samples were collected by jugular venipuncture from all ewes before the morning feeding $(0700 \mathrm{~h})$ on day- 1 of the experiment (before mating), day-120 of gestation, parturition day, day-30 and day-60 postpartum. At each collection, a 10-mL aliquot was taken into vacutainer tubes, without Ethylenediaminetetraacetic acid (EDTA)additive for serum collection $[10,11]$. After blood collection, serum was obtained by centrifugation at $2400 \times g$ at $4{ }^{\circ} \mathrm{C}$ for $15 \mathrm{~min}$ and then frozen at $-20^{\circ} \mathrm{C}$ until analysis. Serum concentrations of glucose and non-esterified fatty acid (NEFA; $\mathrm{mg} / \mathrm{dL}$ ) were analyzed using a commercial kit through a semi-automated analyzer (RX Monza; Randox Laboratories, Crumlin, UK).

\subsection{Statistical Analysis}

All data obtained from each experiment were analyzed using a complete randomized design with repeated measurements using the PRO two-way ANOVA SAS (2003). The model of the reproductive performance of ewes was as follows: the pregnancy rate/ewes in heat, twining rate, lambing rate, abortion rate, fecundity rate, prolificacy rate, fecundity, and prolificacy, were analyzed by the Chi-square $\left(\chi^{2}\right)$ test, using [12] to evaluate the effect of treatments. The Chi-square $\left(\chi^{2}\right)$ test was used to compare between each two groups.

\section{Results}

\subsection{Diet Composition}

The ingredients and chemical composition of the different diets tested in this study are detailed in Table 1. The observed variations are attributed in large part to the diet composition. The amounts of fiber vary according to the source of fiber SFH levels in each treatment group. 
Table 1. Compositions of the experimental diets.

\begin{tabular}{|c|c|c|c|c|}
\hline \multirow{2}{*}{ Ingredient (\%) } & \multicolumn{4}{|c|}{ Treatment * } \\
\hline & $\mathrm{C}$ & S12 & S20 & S28 \\
\hline Barley grain & 32.56 & 20.41 & 22.21 & 29.20 \\
\hline Palm kernel meal & 20.00 & 20.00 & 20.00 & 9.25 \\
\hline Wheat straw & 16.30 & 16.33 & 6.51 & \\
\hline Sunflower meal & 13.80 & 13.84 & 13.71 & 16.03 \\
\hline Sunflower hulls & 0.00 & 12.00 & 20.00 & 28.00 \\
\hline Wheat bran & 10.00 & 10.00 & 10.00 & 10.00 \\
\hline Molasses & 5.00 & 5.00 & 5.00 & 5.00 \\
\hline Acid buffer & 0.8 & 0.8 & 0.8 & 0.8 \\
\hline Limestone & 0.72 & 0.74 & 0.87 & 0.90 \\
\hline Salt & 0.52 & 0.56 & 0.57 & 0.49 \\
\hline Vitamin and mineral premix & 0.30 & 0.30 & 0.30 & 0.30 \\
\hline \multicolumn{5}{|l|}{ Chemical composition } \\
\hline Dry matter (\%) & 90.39 & 88.47 & 88.74 & 88.54 \\
\hline Protein $(\%)$ & 14.6 & 15.7 & 13.3 & 14.1 \\
\hline Fiber $(\%)$ & 18.26 & 20.78 & 21.81 & 22.16 \\
\hline Fat $(\%)$ & 4.02 & 4.35 & 4.00 & 4.35 \\
\hline Cellulose (\%) & 19.77 & 21.35 & 18.51 & 21.06 \\
\hline Hemicellulose (\%) & 6.96 & 8.49 & 9.13 & 10.87 \\
\hline Gross energy (kcal/kg) & 3641 & 3613 & 3744 & 3710 \\
\hline Acid detergent fiber $(\%)$ & 28.46 & 30.25 & 29.55 & 30.66 \\
\hline Neutral detergent fiber (\%) & 37.59 & 38.74 & 36.50 & 41.52 \\
\hline Lignin (\%) & 7.37 & 6.99 & 8.88 & 9.07 \\
\hline
\end{tabular}

\subsection{The Effects of Treatment on the General Performance of Ewes}

Table 2 shows the effects of feeding different levels of SFH as a source of fiber on the feed intake of Awassi ewes. Treatment had a significant effect on the feed intake of the ewes during the late gestation ( $30 \mathrm{~d}$ prepartum) and parturition day $(p=0.05)$, with the S12 and S20 groups having lower feed intakes than the C and S28 groups daily feed intake was significantly $(p<0.05)$ low during late gestation in comparable with other time periods.

Table 2. The effects of different levels of sunflower hulls in total mixed ration on Awassi ewe's feed intake (kg) during different reproduction stages.

\begin{tabular}{cccccccc}
\hline \multicolumn{7}{c}{ Reproduction Stages } \\
\hline Treatments & $\begin{array}{c}\text { Mating } \\
\text { Period }\end{array}$ & $\begin{array}{c}\text { Late } \\
\text { Gestation }\end{array}$ & $\begin{array}{c}\text { Parturition } \\
\text { Day }\end{array}$ & $\begin{array}{c}\text { 30 Days } \\
\text { Postpartum }\end{array}$ & $\begin{array}{c}\text { 60 Days } \\
\text { Postpartum }\end{array}$ & SEM & $p$-Value \\
\hline C & $1.29^{\mathrm{B}}$ & $1.13^{\mathrm{aC}}$ & $1.91^{\mathrm{aA}}$ & $1.75^{\mathrm{A}}$ & $1.46^{\mathrm{AB}}$ & 0.18 & 0.01 \\
S12 & $1.35^{\mathrm{B}}$ & $0.53^{\mathrm{bC}}$ & $1.57^{\mathrm{bAB}}$ & $1.43^{\mathrm{A}}$ & $1.38^{\mathrm{AB}}$ & 0.17 & 0.03 \\
S20 & 1.38 & $0.90^{\mathrm{b}}$ & $1.56^{\mathrm{b}}$ & 1.66 & 1.17 & 0.14 & 0.13 \\
S28 & 1.42 & $1.22^{\mathrm{a}}$ & $1.84^{\mathrm{a}}$ & 1.75 & 1.41 & 0.21 & \\
SEM & 0.04 & 0.86 & 0.06 & 0.06 & 0.90 & \\
\hline -value & 0.91 & 0.05 & 0.05 & 0.94 & & \\
\hline
\end{tabular}

C: $0 \%$ sunflower hulls; S12, $12 \%$ sunflower hulls; S20, 20\% sunflower hulls; S28, $28 \%$ sunflower hulls: ${ }^{\text {a,b }}$ means within columns with different superscript letters significantly differ (group effect); ${ }^{A}, B, C$ means within a row with different superscript letters significantly differ).

Table 3 shows the effects of feeding different levels of SFH as a source of fiber on the body weight of Awassi ewes. There is no significant effect for the levels of sunflower hulls in total mixed ration on Awassi ewe's body weight during each reproductive stage. The body weight of ewes was affected significantly $(p<0.5)$ by the reproductive stages of ewes in each group. The highest body weight was observed at late gestation which significantly $(p<0.05)$ higher than the body weight at 60-days postpartum and during the mating period. Body condition score was significantly $(p<0.05)$ higher during late gestation compared to other periods (Figure 1). 
Table 3. The effects of different levels of sunflower hulls in total mixed ration on Awassi ewe's body weight (kg) during different reproduction stages.

\begin{tabular}{|c|c|c|c|c|c|c|c|}
\hline \multirow[b]{2}{*}{ Treatments } & \multirow[b]{2}{*}{$\begin{array}{l}\text { Mating } \\
\text { Period }\end{array}$} & \multicolumn{6}{|c|}{ Reproduction Stages } \\
\hline & & $\begin{array}{c}\text { Late } \\
\text { Gestation }\end{array}$ & $\begin{array}{c}\text { Parturition } \\
\text { Day }\end{array}$ & 30-Day Postpartum & $\begin{array}{c}\text { 60-Day } \\
\text { Postpartum }\end{array}$ & SEM & $p$-Value \\
\hline $\mathrm{C}$ & $41.23^{C}$ & $66.67^{\mathrm{A}}$ & $61.04 \mathrm{AB}$ & $62.05^{\mathrm{AB}}$ & $60.90^{B}$ & 1.31 & 0.020 \\
\hline S12 & $40.71^{C}$ & $68.85^{\mathrm{A}}$ & $63.00 \mathrm{AB}$ & $59.11^{\mathrm{B}}$ & $59.28^{B}$ & 1.27 & 0.008 \\
\hline S20 & $41.47^{\mathrm{C}}$ & $65.56^{\mathrm{A}}$ & $60.07 \mathrm{AB}$ & $59.75 \mathrm{~A}^{\mathrm{B}}$ & $57.71^{\mathrm{B}}$ & 1.11 & 0.015 \\
\hline S28 & $41.04^{C}$ & $68.025^{\mathrm{A}}$ & $62.46^{\mathrm{B}}$ & $59.615^{\mathrm{B}}$ & $58.68^{\mathrm{B}}$ & 1.25 & 0.05 \\
\hline SEM & 0.36 & 1.09 & 1.05 & 1.35 & 1.40 & & \\
\hline$p$-value & & & 0.73 & 0.76 & 0.90 & & \\
\hline
\end{tabular}

C: $0 \%$ sunflower hulls; S12, $12 \%$ sunflower hulls; S20, $20 \%$ sunflower hulls; S28, $28 \%$ sunflower hulls: ${ }^{A, B, C}$ means within a row with different superscript letters significantly differ (reproductive stage effect).

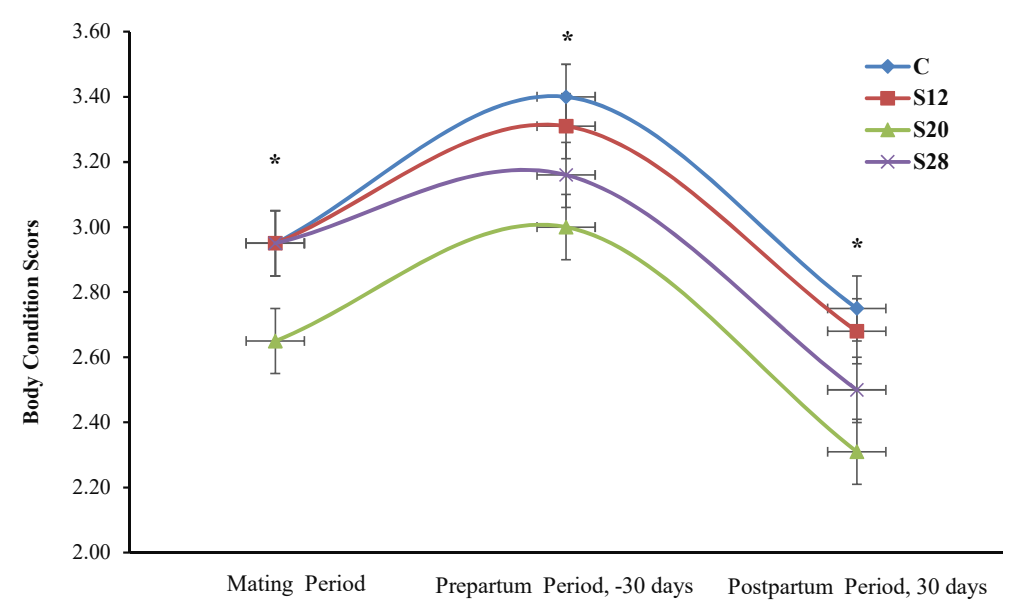

Figure 1. The effects of different levels of sunflower hulls in total mixed ration on body condition score $(1-5)$ during late different reproductive stages. * period effect $(p<0.001)$.

\subsection{The Effects of Treatment on Some Blood Parameters of Ewes}

Table 4 show the effect of feeding different levels of SFH as a source of fiber on Awassi ewe's glucose level $(\mathrm{mg} / \mathrm{dL})$ during different reproductive stages. A significant effect of the treatments $(p=0.02)$ on glucose levels were found with higher levels in ewes from the S20 group than C, S12, and S28 groups during 30 days postpartum. However, significant stages were observed between the late gestation and the mating period on glucose level. Ewes from groups S20 and S28 showed a significant increase in the glucose level at parturition in comparison with other physiological periods.

Table 4. The effects of different levels of sunflower hulls in total mixed ration on Awassi ewe's glucose level (mg/dL) during different reproductive stages.

\begin{tabular}{cccccccc}
\hline \multicolumn{7}{c}{ Reproductive Stages } \\
\hline \multirow{2}{*}{ Treatment } & $\begin{array}{c}\text { Mating } \\
\text { Period }\end{array}$ & $\begin{array}{c}\text { Late } \\
\text { Gestation }\end{array}$ & $\begin{array}{c}\text { Parturition } \\
\text { Day }\end{array}$ & $\begin{array}{c}\text { 30 Days } \\
\text { Postpartum }\end{array}$ & $\begin{array}{c}\text { 60 Days } \\
\text { Postpartum }\end{array}$ & SEM & $p$-Value \\
& 35.27 & 39.10 & 48.76 & $38.84 \mathrm{~b}$ & 43.01 & 3.58 & 0.19 \\
C12 & 48.12 & 43.85 & 55.02 & $46.99 \mathrm{~b}$ & 53.57 & 3.57 & 0.24 \\
S20 & $35.94 \mathrm{C}$ & $47.35 \mathrm{BC}$ & $68.74 \mathrm{~A}$ & $74.08 \mathrm{cB}$ & $59.49 \mathrm{~B}$ & 4.58 & 0.0001 \\
S28 & $43.24 \mathrm{~B}$ & $55.17 \mathrm{~B}$ & $83.60 \mathrm{~A}$ & $52.12 \mathrm{bB}$ & $55.65 \mathrm{~B}$ & 7.15 & 0.003 \\
SEM & 2.98 & 2.31 & 16.50 & 4.48 & 4.11 & & \\
$p$-value & 0.27 & 0.10 & 0.11 & 0.02 & 0.55 & & \\
\hline
\end{tabular}

C: $0 \%$ sunflower hulls; S12, 12\% sunflower hulls; S20, 20\% sunflower hulls; S28, 28\% sunflower hulls; b,c means within column with different superscript letters significantly differ (group effect); A,B,C means within a row with different superscript letters significantly differ (reproductive stage effect). 
Figure 2 show the effect of feeding different levels of SFH as a source of fiber on Awassi ewe's non-esterified fatty acid (NEFA) level at late gestation and parturition. At late gestation, a significantly $(p<0.01)$ higher concentration of blood serum NEFA was reported for ewes from the $C$ group compared with other groups, but ewes from the S28 group showed a significantly lower NEFA compared with the other groups. Furthermore, significantly lower $(p<0.05)$ NEFA levels at parturition were reported for ewes from the S20 group compared with the S12 group.

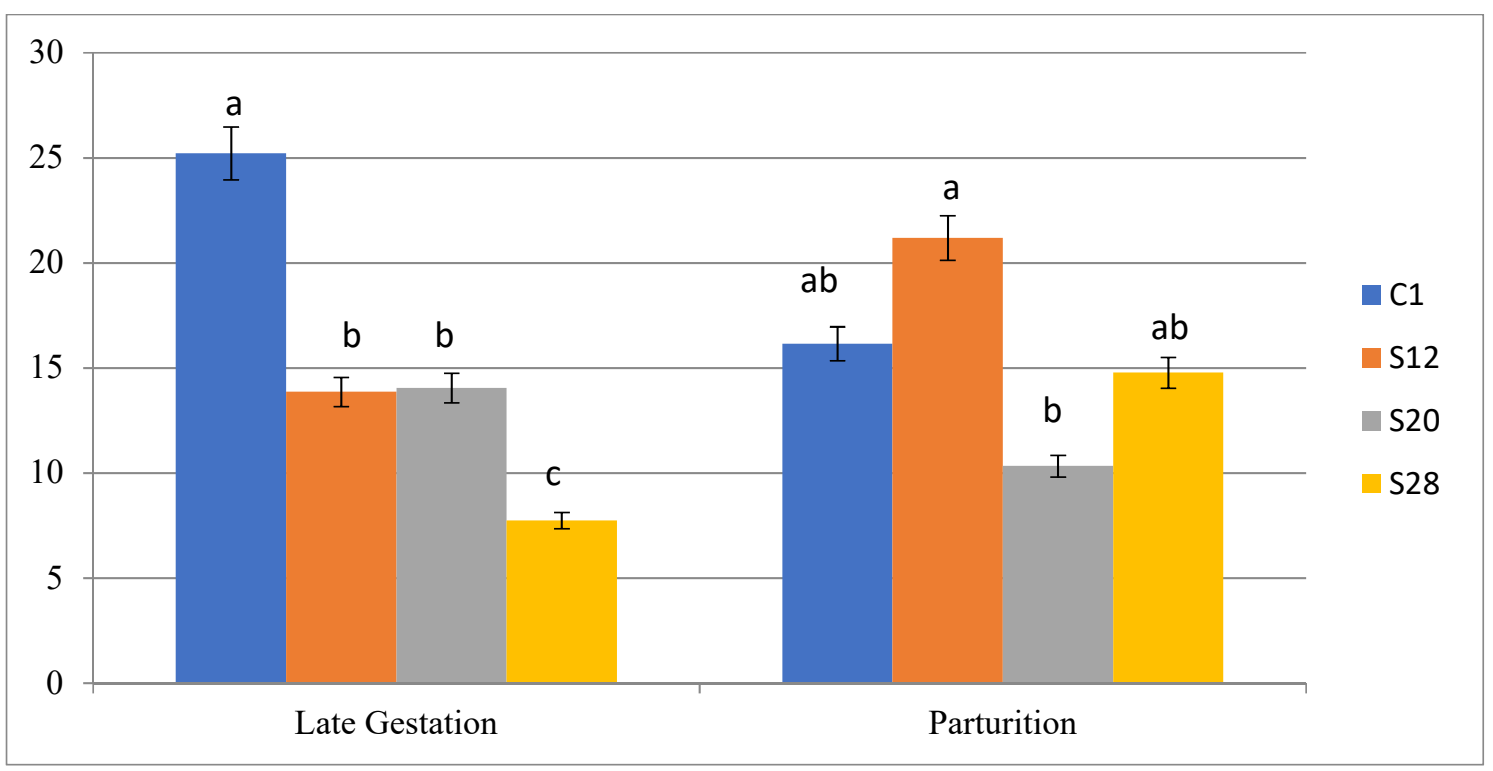

Figure 2. The effects of different levels of sunflower hulls in total mixed ration on Awassi ewe's nonesterified fatty acids level $(\mathrm{mg} / \mathrm{dL})$ during different physiological periods. Different letters indicate significant differences.

\subsection{The Effects of Treatments on the Reproductive Performance of Pregnant Awassi Ewe}

The reproductive performance data are shown in Table 5 . There was no effect $(p>0.05)$ of treatments on reproductive parameters of Awassi ewes except for conception rate where there were significant differences $(p=0.05)$. The effects of different levels of sunflower hulls in total mixed ration on pregnancy and fecundity rate were not significant $(p=0.90$ and $p=0.14)$. Moreover, the current results showed no significant $(p=0.87)$ effect of the treatments on the twining rate, which was lower for ewes from the C, S20 and S28 groups $(5.88,5.56$, and $5 \%$, respectively). The prolificacy rate was non significantly higher $(p=0.14)$ in the C and S28 (88.23 and 80.00, respectively). Minor non-significant variations were reported for other reproductive parameters in favor of the ewes from groups C and S28 such as lambing rate, fecundity, and lamb survivability (Table 5 and Figure 3).

Table 5. The effects of different levels of sunflower hulls in total mixed ration on reproductive parameters of Awassi ewes.

\begin{tabular}{ccccccc}
\hline TreatmentItem & C & S12 & S20 & S28 & $\mathbf{X}^{\mathbf{2}}$ & $\boldsymbol{p}_{\text {-Value }}$ \\
\hline Number of services & $1.27 \pm 0.21^{\mathrm{b}}$ & $1.60 \pm 0.22 \mathrm{ab}$ & $1.50 \pm 0.18 \mathrm{ab}$ & $2.00 \pm 0.19 \mathrm{a}$ & & 0.05 \\
per conception & $94.44(17 / 18)$ & $94.73(18 / 19)$ & $90.00(18 / 20)$ & $95.23(20 / 21)$ & 0.59 & 0.90 \\
Pregnancy rate\% & $5.88(1 / 17)$ & $11.11(2 / 18)$ & $5.56(1 / 18)$ & $5.00(1 / 20)$ & 0.69 & 0.87 \\
Twining rate\% & $65.71(12 / 17)$ & $61.07(11 / 18)$ & $66.63(12 / 18)$ & $69.81(14 / 20)$ & 0.46 & 0.92 \\
Lambing rate\% & $83.33(15 / 18)$ & $52.63(10 / 19)$ & $44.82(13 / 20)$ & $80.00(16 / 20)$ & 5.45 & 0.14 \\
Fecundity rate & $88.23(15 / 17)$ & $55.55(10 / 18)$ & $72.22(13 / 18)$ & $80.00(16 / 20)$ & 5.37 & 0.14 \\
Prolificacy rate &
\end{tabular}

C: $0 \%$ sunflower hulls; S12, 12\% sunflower hulls; S20, 20\% sunflower hulls; S28, 28\% sunflower hulls. a,b significantly different. SEM, standard error means. 


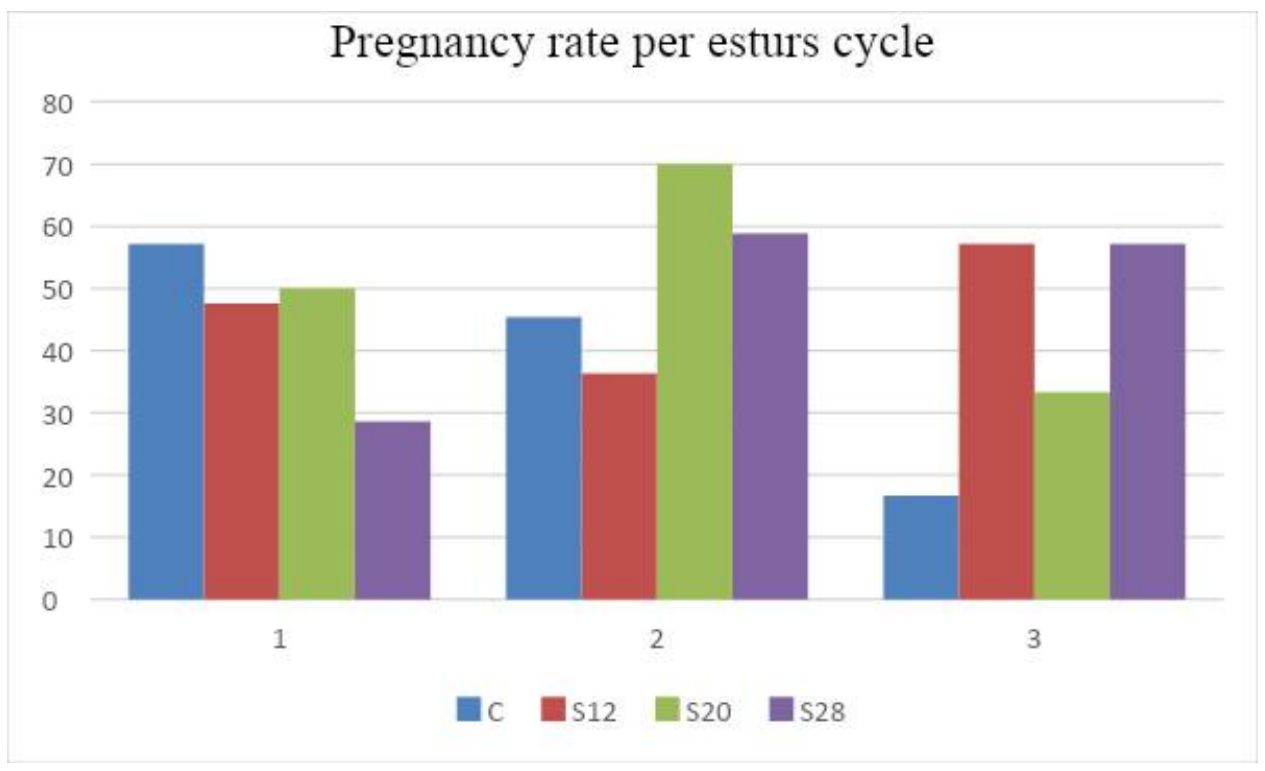

Figure 3. The effect of feeding different levels of SFH as a source of fiber on the pregnancy rate of Awassi ewes per estrus.

\section{Discussion}

Treatments had a significant effect on the DFI of the ewes during the late gestation (30 d prepartum) and parturition day, with the S12 and S20 groups having lower feed intakes than the $\mathrm{C}$ and $\mathrm{S} 28$ groups. The results revealed that BW at late gestation was significantly higher than the BW at 60-days postpartum and during the mating period. This increase in BW during the late gestation period is viewed as logical due to the additional weights of fetus, fetal membranes, and fetal fluid during the late gestation period. BCS was significantly higher during late gestation compared to the other stages. This indicates that the type of diet (TMR) is beneficial for annual ewes during lactation, which coincides with the results of $[13,14]$.

In formulating a TMR, it is fundamental to cover the energy, protein, minerals and vitamins requirements of sheep [3]. Feed intake and body weight for ewes play an important role in measuring feed efficiency. Ref. [15] reported that complete feed supplementation in the form of the block for grazing sheep during feed scarcity in the semi-arid zone helped to increase the BW due to the availability of better nutrients when compared to grazing sheep. In this study, the NDF content of the TMR was increased in the C, S12, S20, and S28 groups $(36.50,37.59,39.74$, and $41.52 \mathrm{NDF})$, respectively (Table 1$)$. This corresponds with a study by [16], who reported positive effects of dietary physical effective neutral detergent fiber (peNDF) on dry matter intake and BW, as well as physical fill. However, low peNDF content in the diet increased the feed intake and BW of ruminants. Ref. [17] reported that dietary substrates such as lignin interact with cellulose and hemicellulos in the forages and consequently negatively affect their digestion and absorption. Simeng [18] concluded that thermal and chemical treatment of biomass residues of SFH may convert it into high-value products. Lignin content in the diet of the C, S12, S20, and S28 groups appeared to have no significant effect on performance. It seems that grinding and pelleting the feed, as well as reducing the particle size may decrease the negative effects of lignin on fiber fermentation. These results are consistent with the report of Simeng [18], but it does not correspond to the effect of lignin as an important factor in reducing the digestibility of forage fiber [19]. Moreover, previous studies have reported that the rate of NDF degradation increases with a decrease in the lignin content of the forage [20,21]. The findings of the current study supported the idea that lignin limited the rate of NDF degradation due to the high percentage of hemicelluloses (NDF) for the S28 group. 
There was no significant effect of different levels of sunflower hulls in TMR on all reproductive parameters except S/C, which was significantly higher in S28 than in other groups. Diethylstilbestrol (lignins) is one of the most important phytoestrogens, which is a naturally occurring phytochemicals found in plants and plant products. These are structurally and functionally similar to $17 \beta$-estradiol (isoflavones) or synthetic estrogens. One of the principal phytoestrogens is lignins (for example, enterolactone, and enterodiol), which are derived from precursors in the diet by the gut microflora. Phytoestrogens stimulate the reproductive tract of ewes and enlarge mammary glands, which may secrete a milk-like fluid. Hypertrophic effects are observed in the uterus, external genitalia appear swollen, and increased secretion of cervical mucus may be visible from the vulva. In sheep, rodents, horses, cattle, and pigs, increased ingestion of phytoestrogens induces marked estrogenic clinical signs including edematous vaginal and cervical tissue, modified development of ovarian follicles, an increase in hemorrhagic follicles, abnormal follicular waves, ovarian dysfunction, early embryonic death, miscarriage, suppression of the hormone surge (viz. luteinizing and follicle stimulating hormones), repeat breeding, and estrogenic syndrome (viz. mammary gland hypertrophy and milk-like secretions from elongated teats) [13]. In the males, alterations in testis development and a decrease in sperm count is induced [14]. This can explain the increase of S/C in S28 group that had more lignin (phytoestrogen) content than other groups.

The blood glucose level was significantly higher in S20 group than the C, S12, and S28 groups during 30 days postpartum. The S20 and S28 groups showed a significant increase in glucose level at parturition in comparison with other reproductive stages. The NDF content (39.74 and 41.52) in the current study corresponds to the results of [22] who demonstrated that high NDF intake increases the animal attempts to meet its energy requirement. NEFA concentration in blood was negatively correlated with dry matter intake (DMI), especially at late gestation, which led to elevated levels of NEFA as indication of negative energy balance [23]. The high NEFA concentrations in the serum of the C, S12, and S20 treatment groups during late gestation does not correspond to the normal range of glucose and NEFA in an intensive system for pre-partum. At late gestation, a significantly $(p<0.01)$ higher concentration of blood NEFA was reported for ewes from the $C$ group compared with other groups. Furthermore, significantly lower $(p<0.05)$ NEFA levels at parturition were reported for ewes from the S20 group compared with S12 group. The S28 group had high fiber and lignin contents, which resulted in decreased $(p<0.05)$ glucose concentrations during the parturition period.

\section{Conclusions}

Generally, total mixed rations are not preferable to be used alone in the late gestation period. Sunflower hull can be used as a cheap source of fiber in TMR without adverse effects on the health and reproductive traits of ewes. Increasing the level of sunflower hull to $28 \%$ can affect fertility and increase the number of services per conception due to its high content of lignin (phytoestrogen).

Author Contributions: Conceptualization, A.S.A. and M.M.A. (Mutassim M. Abdelrahman); methodology, M.M.A. (Mohsen M. Alobre); software, I.A.A.; validation, R.U.K., A.A.S. and M.M.A. (Mutassim M. Abdelrahman); formal analysis, M.M.A. (Mohsen M. Alobre); investigation, H.H.A.-B.; resources, I.A.A.; data curation, R.U.K.; writing—original draft preparation, M.M.A. (Mohsen M. Alobre); writing-review and editing, R.U.K.; visualization, A.S.A.; supervision, H.H.A.-B.; project administration, I.A.A.; funding acquisition, M.M.A. (Mutassim M. Abdelrahman). All authors have read and agreed to the published version of the manuscript.

Funding: The authors would like to extend their appreciation to the Deanship of Scientific Research at King Saud University for funding this work through research project number RG-1436-021.

Institutional Review Board Statement: This research work was approved by the departmental committee on ethics and animal welfare, King Saud University, Saudi Arabia (KSU/CFAS/2019/3421).

Informed Consent Statement: Not applicable. 
Data Availability Statement: Data are available in thesis.

Conflicts of Interest: The authors declare no conflict of interest.

\section{References}

1. Wirsenius, S.; Azar, C.; Berndes, G. How much land is needed for global food production under scenarios of dietary changes and livestock productivity increases in 2030? Agric. Syst. 2010, 103, 621-638. [CrossRef]

2. Islam, R.; Redoy, M.; Shuvo, A.; Sarker, M.; Akbar, M.; Al-Mamun, M. Effect of pellet from total mixed ration on growth performance, blood metabolomics, carcass and meat characteristics of Bangladeshi garole sheep. Progress. Agric. 2017, 28, 222-229. [CrossRef]

3. Alhidary, I.A.; Abdelrahman, M.M.; Alyemni, A.H.; Khan, R.U.; Al-Saiady, M.Y.; Amran, R.A.; Alshamiry, F.A. Effect of alfalfa hay on growth performance, carcass characteristics, and meat quality of growing lambs with ad libitum access to total mixed rations. Rev. Bras. Zootec. 2016, 45, 302-308. [CrossRef]

4. FAO. Statistical Yearbook; FAO: Rome, Italy, 2014; Volume 66.

5. Rumball, C.W.; Harding, J.E.; Oliver, M.H.; Bloomfield, F.H. Effects of twin pregnancy and periconceptional undernutrition on maternal metabolism, fetal growth and glucose-insulin axis function in ovine pregnancy. J. Physiol. 2008, 586, 1399-1411. [CrossRef] [PubMed]

6. Abdelrahman, M.M.; Alhidary, I.; Alyemni, A.H.; Khan, R.U.; Bello, A.R.; Al-Saiady, M.Y.; Amran, R.A. Effect of alfalfa hay on rumen fermentation patterns and serum biochemical profile of growing Awassi lambs with ad libitum access to total mixed rations. Pak. J. Zool. 2017, 49, 1519-1522. [CrossRef]

7. Sewalt, V.J.; Oliveira, W.D.; Glasser, W.G.; Fontenot, J.P. Lignin impact on fiber degradation: 2. A Model Study Using Cellulosic Hydrogels. J. Sci. Food Agric. 1997, 71, 204-208. [CrossRef]

8. National Research Council. Nutrient Requirements of Small Ruminants: Sheep, Goats, Cervids, and New World Camelids; National Research Council: Ottawa, ON, Canada, 2007.

9. Santucci, P.M.; Maestrini, O. Body conditions of dairy goats in extensive systems of production: Method of estimation. In Annales de Zootechnie; Institut National de la Recherche Agronomique: Paris, France, 1985; pp. 473-474.

10. Donovan, J.; Brown, P. Removal of blood from laboratory mammals and birds: First report of the BVA/FRAME/RSPCA/UFAW Joint working group on refinement. Lab Anim. 1993, 27, 1-22.

11. Holtgrew-Bohling, K. Large Animal Clinical Procedures for Veterinary Technicians, 2nd ed.; Elsevier: Amsterdam, The Netherlands, 2012.

12. SAS Institute. SAS User's Guide, 8th ed.; SAS Institute: Cary, NC, USA, 2003.

13. Reed, K.F.M. Fertility of herbivores consuming phytoestrogen-containing Medicago and Trifolium species. Agriculture 2016, 6, 35. [CrossRef]

14. Mostrom, M.; Evans, T.J. Phytoestrogens. In Reproductive and Developmental Toxicology; Academic Press: Cambridge, MA, USA, 2011; pp. 707-722.

15. Chaturvedi, O.H.; Bhatt, R.S.; Sahoo, A. Nutrient utilization in grazing ewes supplemented with complete feed blocks during scarcity in semi-arid region. Indian J. Small Rumin. 2014, 20, 114-117.

16. Allen, M.; Oba, M. Fiber digestibility of forages. In Proceedings of the 57th Minnesota Nutrition Conference, St. Paul, MN, USA, 23-25 September 1996; p. 151.

17. Bonawitz, N.D.; Chapple, C. The genetics of lignin biosynthesis: Connecting genotype to phenotype. In Annual Review of Genetics; Annual Reviews: San Mateo, CA, USA, 2010; Volume 44, pp. 337-363.

18. Li, S.; Chen, G. Thermogravimetric, thermochemical, and infrared spectral characterization of feedstocks and biochar derived at different pyrolysis temperatures. Waste Manag. 2018, 78, 198-207. [CrossRef] [PubMed]

19. Jung, H.G.; Mertens, D.R.; Payne, A.J. Correlation of acid detergent lignin and Klason lignin with digestibility of forage dry matter and neutral detergent fiber. J. Dairy Sci. 1997, 80, 1622-1628. [CrossRef]

20. Oliver, A.L.; Grant, R.J.; Pedersen, J.F.; O’Rear, J. Comparison of brown midrib-6 and -18 forage sorghum with conventional sorghum and corn silage in diets of lactating dairy cows. J. Dairy Sci. 2004, 87, 637-644. [CrossRef]

21. Vargas-Bello-Pérez, E.; Mustafa, A.F.; Seguin, P. Effects of feeding forage soybean silage on milk production, nutrient digestion, and ruminal fermentation of lactating dairy cows. J. Dairy Sci. 2008, 91, 229-235. [CrossRef] [PubMed]

22. Harper, K.J.; Barber, D.G.; Callow, M.; McNeill, D.M.; Poppi, D.P. Assessment of the Indf of Subtropical Pastures. Anim. Prod. Aust. 2014, 30, 320.

23. Ingvartsen, K.L.; Munksgaard, L.; Nielsen, V.K.M.; Pedersen, L.J. Responses to repeated deprivation of lying down on feed intake, performance and blood hormone concentration in geoting bulls. Acta Agric. Scan. 2006, 49, 260-265. 